Max-Planck-Institut für demografische Forschung

Max Planck Institute for Demographic Research

Doberaner Strasse 114 - D-18057 Rostock · GERMANY

Tel +49 (0) 3812081 - 0; Fax +49 (0) 3812081 - 202;

http://www.demogr.mpg.de

MPIDR WORKING PAPER WP 2001-004

JANUARY 2001

\title{
Transitions from Home to Marriage of Young Americans
}

\author{
Arnstein Aassve (aassve@ demogr.mpg.de) \\ Simon Burgess \\ Andrew Chesher \\ Carol Propper
}

This working paper has been approved for release by: Francesco C. Billari (billari@ demogr.mpg.de) Head of the Research Group on the Demography of Early Adulthood.

(C) Copyright is held by the authors.

Working papers of the Max Planck Institute for Demographic Research receive only limited review. Views or opinions expressed in working papers are attributable to the authors and do not necessarily reflect those of the Institute. 


\title{
Transitions from Home to Marriage of Young Americans
}

\author{
Arnstein Aassve* Simon Burgess ${ }^{* *} \quad$ Andrew Chesher ${ }^{* * *}$ \\ Carol Propper** \\ * Max Planck Institute for Demographic Research, \\ Doberaner Str. 114, \\ 18057 Rostock, Germany. ${ }^{1}$ \\ ** Department of Economics, University of Bristol, \\ 8 Woodland Road, BS8 1TN Bristol, UK, \\ CASE and CEPR. \\ *** Department of Economics, University College London, \\ Gower Street, WC1E 6BT London, UK.
}

30th January 2001

${ }^{1}$ Corresponding author: aassve@demogr.mpg.de, Tel: 00493812081 195, Fax: 00493812081495 


\begin{abstract}
The paper examines the impact of income on the transitions between home, living independently and first marriage of young Americans. A matching model is outlined, similar to that used in theories of job search, to explain the probability of marriage and living alone. A multiple state, multiple transition model which allows for correlated heterogeneity on the first and subsequent transitions is estimated. The results show that income has a strong and significant effect. The impact of unobserved heterogeneity is examined in detail. The impact of the young person's earnings on the transitions is explored through simulation.

Keywords: Marriage, Search model, Multi-state Multi-cycle model, Correlated Heterogeneity.

JEL Classification: C5, J1
\end{abstract}




\section{Introduction}

The early years of adulthood of Americans are times of change in living arrangements. Individuals leave their parental home, live alone, form partnerships, separate and reform partnerships. These early transitions shape later household formation and dissolution patterns. The last three decades have witnessed large changes in rates of household formation and dissolution in the US. Age at marriage and rates of non-marriage, extra-marital childbearing and divorce have all risen. Many of these changes are accounted for by the behaviour of those in early adulthood.

This paper focuses on the decisions of young Americans to leave home, live independently, and form first stable partnerships. The route to stable partnership formation ("marriage ${ }^{1 ")}$ ) is not always a direct passage from the parental home to marriage. Many individuals leave home to live alone from where they marry. And some return home before leaving again, either to live alone or to marry. For some people there are many alternations between the parental home and living alone before marriage.

This paper presents an econometric model of this transition process and estimates of its parameters obtained using data from the National Longitudinal Survey of Youth (NLSY) covering 1979 - 1992. Of particular interest is the extent to which transitions are affected by the financial resources of the young person and their family because these resources can be altered by changes in the tax and benefit system and by highs and lows in economic activity. In contrast with some earlier studies (see Buck and Scott (1993) and Haurin et al (1993)) this analysis reveals a strong effect of income on the rates of transition between states. Higher parental income delays transitions out of home and into marriage, while higher own income accelerates them. The practical significance of alternative income streams is investigated by microsimulation of the estimated transition model.

A search theoretic model is presented in which individuals are forward looking and make decisions about their living arrangements by comparing the present and future benefits and costs of alternative actions. The decision to leave home is estimated as a multiple state, multiple spell transition model in which individuals may make many transitions between living at home and living independently before marrying. Although the econometric

\footnotetext{
${ }^{1}$ The term "marriage" is used to describe legal marriage or stable cohabitation with a partner.
} 
analysis includes controls for some individual characteristics there are many unobserved influences on transition rates so in the analysis there is explicit allowance for unobserved heterogeneity which is allowed to have correlated effects on first and subsequent transitions.

The paper is organised as follows. In Section 2 the patterns in household formation in young Americans are outlined, the transition types and rates in the NLSY sample are examined, and the literature which has examined the impact of income on these early transitions is reviewed. Section 3 presents the analytic framework which informs the estimation. Section 4 presents the econometric model. Section 5 describes the data. Section 6 contains the results. Section 7 examines the impact of resources on transitions in greater detail using simulated data generated using the estimated model. Section 8 concludes.

\section{Related previous research}

Changes in household formation and dissolution have important policy implications. There has been concern over the "retreat from marriage" among young people. Much research effort has been devoted to understanding the impact of the public sector on this behaviour; for example, investigating whether public support for those who have children outside partnerships results in fatherless families. Moffitt (1990) found that the welfare payment Aid to Families with Dependent Children (AFDC) reduces the probability of marriage for both men and women. Others, such as Lichter et al (1992) explain the retreat from marriage as the result of fewer good marriage opportunities for women. Yet others explain it as a result of better labour market opportunities for women (e.g. Greenstein (1995)). From a different perspective, Akerlof et al (1985) have sought to account for longer run changes in patterns of household formation as a consequence of technical change: the introduction of more reliable methods of contraception. Their model predicts that such changes will delay marriage. Clearly, the factors that affect household formation amongst the young are many: our paper focuses on the impact of incomes of the young and their parents.

Most of the changes in household formation and dissolution are accounted for by the behaviour of those aged 18-30 (Rindfuss (1991)). Leaving home for the first time is concentrated amongst 18-21 year olds. Young women leave home earlier than young men, and marry earlier (Goldscheider (1985)). 
Marriage rates peak for women in their mid 20s, and for men in their late 20s. Cohabitation is increasing, both as a precursor to marriage, and for some groups, as a substitute (Lillard and Brien (1995)). For that reason marriage and stable cohabitation are treated as the same state here.

The evidence on the importance of income in determining these transitions is mixed. Using 1984 SIPP data, Avery et al (1992) found that both the earnings and the employment status of young adults were important determinants of the transition from home to both independent living and marriage. They found young adults of both sexes who are employed, and those who have higher earnings, to be more likely to leave home by both routes. They found family resources had an impact only through the effect on leaving home via marriage, and had no impact on leaving home for unmarried independence. On the other hand, Haurin et al (1993) using NLSY data for 1987 found that the respondent's potential real wage had little effect on the tendency to live alone, and nor were AFDC payments clearly related to living alone except for young women. Buck and Scott (1993) distinguished between leaving home to live with a partner and leaving home to live independently. Using PSID data to estimate a competing risks model for these two destinations they found little effect of family income, own employment or own income on either event for men or women. Annual work hours had an effect on the probability of marriage but not on the probability of independent living for women, while none of the variables had a significant impact on the probabilities of exiting home to either destination for men. Using an early wave of the NLSY Michael and Tuma (1985) found young whites were more likely to delay marriage when the resources of their family are higher, though this effect was not apparent for other races. McLaughlin et al (1993) and Lichter (1992) found women's economic independence appeared to hasten marriage. Using cross sectional data, Moffitt (1990) found a significant negative impact of AFDC on the probability of marriage. However, these effects were stronger for men than for women, particularly for blacks. 


\section{The role of income in household formation and marriage decisions}

\subsection{A search framework}

A matching model is outlined, similar to that used in theories of job search, to explain the probability of marriage and living alone. A growing literature uses search theory to model marriage. Burdett and Coles (1996), for example, have applied search theory to a pairwise matching process between heterogenous agents to examine the impact of the distribution of quality of partners on duration of time to marriage and the type of matches formed. In this paper the aim is not to solve for the structural parameters of the model but to understand the role played by income in the transition processes.

An individual may be in one of three possible states: living at home with parents (denoted $\mathcal{H}$ ), living alone $(\mathcal{A})$ or being married $(\mathcal{M})$. Since this paper is concerned with transitions before first marriage, marriage is treated as an absorbing state. Starting from $\mathcal{H}$, the individual can move to either $\mathcal{A}$ or $\mathcal{M}$. If in $\mathcal{A}$, the individual can move either to $\mathcal{H}$ or $\mathcal{M}$. Movement between $\mathcal{H}$ and $\mathcal{A}$ can be repeated many times.

The matching model assumes a forward looking individual who seeks to maximise the expected value of her actions. There are two sources of uncertainty in the model.

The first arises from the search and matching process. In each state, the individual will with some probability receive an offer of marriage. An offer is accepted if the quality of the match exceeds the reservation quality for a match (we assume "quality" can be thought of as a one-dimensional attribute). Reservation quality is defined as that level of quality that makes one indifferent between accepting a match and rejecting it, given the current state occupied. The acceptance quality is therefore determined endogenously and will depend upon the expected stream of costs and benefits from the possible states the individual may occupy. As the different states offer different amounts of net utility, there will be a different reservation quality for each origin state.

The second source of uncertainty arises because individuals differ in the value they put on living independently. This value is assumed to be time invariant and known to the individual, but unobserved by the econometrician. Let this be denoted $\varepsilon$. 
Per period utility of being in each state $(\mathcal{H}, \mathcal{A}, \mathcal{M})$ is a function of the income the individual has access to and other state specific influences:

$$
\begin{aligned}
U_{\mathcal{H}} & =U_{\mathcal{H}}\left(y, y_{f}, Z_{\mathcal{H}}\right) \\
U_{\mathcal{A}} & =U_{\mathcal{A}}\left(y, Z_{\mathcal{A}}, \varepsilon\right) \\
U_{\mathcal{M}}(Q) & =U_{\mathcal{M}}\left(y, y_{s}(Q), Z_{\mathcal{M}}\right)
\end{aligned}
$$

where $y$ is the individual's earning potential, $y_{f}$ is the income of the rest of the parental household, $y_{s}$ is the partner's income, $Q$ is the quality of the respondent's actual match, and $Z_{j}$ are vectors of other state-specific influences on utility (these may contain variables in common). Utility in each state is assumed to be increasing in all sources of income. It is assumed that there is less independence in the family home that when living alone.

Assuming stationarity and zero costs of changing state, the expected present value of being in each state can be written as

$$
\begin{aligned}
V_{\mathcal{H}} & =U_{\mathcal{H}}+\delta \theta_{\mathcal{H}} E \max \left[V_{\mathcal{H}}, V_{\mathcal{A}}, V_{\mathcal{M}}(q)\right]+\delta\left(1-\theta_{\mathcal{H}}\right) V_{\mathcal{H}} \\
V_{\mathcal{A}} & =U_{\mathcal{A}}+\delta \theta_{\mathcal{A}} E \max \left[V_{\mathcal{H}}, V_{\mathcal{A}}, V_{\mathcal{M}}(q)\right]+\delta\left(1-\theta_{\mathcal{A}}\right) V_{\mathcal{A}} \\
V_{\mathcal{M}}(Q) & =U_{\mathcal{M}}(Q)+\delta E\left[V_{\mathcal{M}}(Q)\right]
\end{aligned}
$$

where,

$U_{\mathcal{H}}=$ per period utility of being at the parental home

$U_{\mathcal{A}}=$ per period utility of being alone

$U_{\mathcal{M}}(Q)=$ per period utility of being married to a person with quality $Q$

$\delta=$ discount rate

$\theta_{j}=$ the probability of receiving an offer in state $j, j \in\{\mathcal{H}, \mathcal{A}\}$

$q=$ random variable "quality of partner" with c.d.f. $F(\cdot)$

$Q=$ realised value of $q$

Equations (4) and (5) both have the same structure. The individual enjoys utility today in the present state, and in a unit time interval ${ }^{2}$, with some probability $\theta_{j}$, receives an offer of forming a partnership of quality $q$. The expected present value of this is compared to the expected present value of staying in the present state. As marriage is here treated as an

\footnotetext{
${ }^{2}$ It is assumed throughout that the probability of receiving more than one offer in a unit time interval is negligible.
} 
absorbing state equation (6) shows no transitions out of this state. The offer rates $\theta_{j}$ may differ between the states. Although only the behaviour of one individual is explicitly modelled, the potential partners and later an actual partner of this person are also making the decisions outlined above. This means $\theta_{j}$ will depend on the actions of the individual and potential partners

From (4), (5) and (6) the reservation qualities from each origin state can be derived, and hence the transition rates. The former are denoted by $q_{j}^{*}(\cdot)$, $j \in\{\mathcal{H}, \mathcal{A}\}$. Standard techniques (see for example, Mortensen (1986)) show that these will in general depend on all the parameters of the model. Let $\lambda_{i j}$ denote the transition from origin $i$ to destination $j$. These probabilities are the product of the probability that an offer is made and that it is accepted (that is if it is above the reservation quality).

The transition probabilities are:

$$
\begin{aligned}
\lambda_{\mathcal{H} \mathcal{M}} & =\theta_{\mathcal{H}}(\cdot)\left[1-F\left(q_{\mathcal{H}}^{*}(\cdot)\right)\right] \\
\lambda_{\mathcal{A M}} & =\theta_{\mathcal{A}}(\cdot)\left[1-F\left(q_{\mathcal{A}}^{*}(\cdot)\right)\right]
\end{aligned}
$$

The transition between home and alone depends on the trade off between the value of independent living, access to income and possible future marriage chances. Suppose that $\theta_{\mathcal{H}}=\theta_{\mathcal{A}}$. Then the decision to live alone depends solely on current utility, that is $\mathcal{A}$ will be chosen if

$$
U_{\mathcal{A}}=U_{\mathcal{A}}\left(y, Z_{\mathcal{A}}, \varepsilon\right)>U_{\mathcal{H}}\left(y, y_{f}, Z_{\mathcal{H}}\right)
$$

or

$$
\varepsilon>\widehat{\varepsilon}\left(y, y_{f}, Z_{\mathcal{A}}, Z_{\mathcal{H}}\right),
$$

where $\widehat{\varepsilon}$ is the reservation value of $\varepsilon$, equating $V_{\mathcal{A}}$ and $V_{\mathcal{H}}$, because future prospects are identical and so do not affect the decision. If $\theta_{\mathcal{H}} \neq \theta_{\mathcal{A}}$ the reservation value $\widehat{\varepsilon}$ is implicitly determined by $V_{\mathcal{A}}=V_{\mathcal{H}}$ i.e.

$$
U_{\mathcal{A}}\left(y, Z_{\mathcal{A}}, \widehat{\varepsilon}\right)=U_{\mathcal{H}}\left(y, y_{f}, Z_{\mathcal{H}}\right)+\delta\left(\theta_{\mathcal{H}}-\theta_{\mathcal{A}}\right)\left[E \max \left[V_{\mathcal{H}}, V_{\mathcal{A}}, V_{\mathcal{M}}(Q)\right]-V_{\mathcal{H}}\right]
$$

The transition from $\mathcal{H}$ to $\mathcal{A}$ occurs if $\varepsilon>\widehat{\varepsilon}$, and depends on all the parameters of the model.

\subsection{Insights from the search model}

First, consider the effect of own earnings. The decision to live independently can be taken unilaterally by the individual: it is always an option, 
whether the individual currently has an offer of partnership or not. High earnings potential raises the value of this outside option $U_{\mathcal{A}}$ and therefore, other things equal, makes transitions into the state of independent living more likely. This self-reliance effect is the first effect of income on household formation. The value of living in a partnership depends on, among other things, the income of the partner. A higher income partner will yield a better outcome for the respondent, other things equal ${ }^{3}$. This implies that high income individuals will be desirable partners, and will therefore stand a higher chance of receiving offers of marriage. This provides the link to the second effect of the respondent's earnings potential on household formation, the good catch ${ }^{4}$ effect, namely that high earnings potential individuals will receive more marriage offers. Though they will raise their acceptance level accordingly, under standard assumptions (Burdett and Vishwanath (1988)) they will have a higher transition rate into marriage. The self-reliance effect (alternatives to marriage are better for high income individuals) and the good catch effect (high marriage offer rates for high income individuals) have opposite implications for the impact of income on transitions into marriage.

The effect of parental resources may also be mixed. In the decision to leave the parental home, the respondent chooses to leave when her desire for independent living together with her own resources outweigh the attraction of sharing in the family's resources. The fewer the family resources, the smaller the gains from living in the parental home. On the other hand, a high parental income may be another signal of a good catch, in which case a high family income would increase the marriage offer rate, and so increase the rate of departures from home. The good catch family resources effect is only relevant for marriage offers, so unless the arrival rate of offers is much higher when alone than at home, family resources might be expected to have a larger positive effect on the transition from home to marriage than to being alone.

In summary the structural model provides the following insights. First, the reservation quality in each origin state depends on all the parameters of the model. Second, transition rates depend upon the marriage probability distribution, the independence probability distribution, the reservation quality of a match and the distribution of that quality. Third, the decisions of a

\footnotetext{
${ }^{3} \mathrm{~A}$ similar argument applies to individuals living in the parental home.

${ }^{4}$ In the context of a partnership, this effect can be interpreted as meaning that high income individuals are valued as partners and therefore effort will be put into keeping them.
} 
forward looking individual as to one event, say leaving home, will be affected by the values and probabilities attached to the other events which may follow from leaving home. So the transition rates of one process may depend upon variables which affect the other process.

\section{Econometric analysis}

\subsection{Stochastic structure}

The data used here are event histories either terminating in marriage or right censored. A three state $(\mathcal{H}, \mathcal{A}$ and $\mathcal{M})$, multiple spell transition model is employed. All individuals are regarded as starting at age $t^{0}=13$ years in state $\mathcal{H}$. They may make transitions between states, possibly returning to state $\mathcal{H}$, state $\mathcal{M}$ being absorbing. Individuals in states $\mathcal{H}$ and $\mathcal{A}$ are regarded as facing competing independent risks of transiting to the two states not occupied.

Define continuously distributed latent variates $T_{i j}^{r}$ associated with the risk at the $r$ th transition of moving from state $i$ to state $j$, with $i, j \in$ $\mathcal{S}=\{\mathcal{H}, \mathcal{A}, \mathcal{M}\}, r \in\{1,2,3, \ldots\}$. In order to keep the model tolerably simple, and in view of the limits on the information contained in the data, the conditional distributions (given covariates to be introduced shortly) of the variates $T_{i j}^{r}$ are restricted to have distribution functions $F_{i j}^{r}(\cdot \mid \cdot)$ satisfying $F_{i j}^{r}(\cdot \mid \cdot)=F_{i j}^{s}(\cdot \mid \cdot)$ for $r, s>1$ and all $i, j \in \mathcal{S}$.

The hazard functions associated with these variates are denoted by

$$
h_{i j}^{r}\left(s \mid x(s), v^{r}\right) \quad i, j \in\{\mathcal{H}, \mathcal{A}, \mathcal{M}\}, r \in\{1,2\}
$$

where $x(s)$ is a vector of covariates some of which may be time varying and $v^{r}$ is a realisation of a transition number specific time invariant random variable, $V^{r}$, included to capture the influence of unmeasured covariates varying across individuals and assumed to be distributed independently of the observed covariates. The corresponding conditional integrated hazard functions are denoted by

$$
I_{i j}^{r}\left(t \mid x(t), v^{r}\right)=\int_{0}^{t} h_{i j}^{r}\left(s \mid x(s), v^{r}\right) d s .
$$

In this competing risks model transition $r$ from state $i$ to state $k$, is regarded as occurring if $T_{i k}^{r}=\min _{j \neq i, j \in \mathcal{S}}\left(T_{i j}^{r}\right)$. Accordingly the probability of exit from state $i$ to state $k$ at transition $r$ in the age interval $(t, t+d t)$ 
conditional on observed and unobserved covariates is (see e.g. Lancaster (1990)):

$$
h_{i k}^{r}\left(t \mid x(t), v^{r}\right) \exp \left(-\sum_{j=1}^{k} I_{i j}^{r}\left(t \mid x(t), v^{r}\right)\right) d t .
$$

\subsection{The likelihood function}

Individuals are observed from age $t^{0}$ until first entry into state $\mathcal{M}$ or until age $c$ after which the event history is censored. Let $R \geq 0$ be the number of transitions made by an individual. Let $t^{r}$ be age at transition $r$. Let $z^{r}=\min \left(t^{r}, c\right)-t^{r-1}, 1<r \leq R$, and let $1_{[\mathcal{C}]}=1$ if $\mathcal{C}$ is true and 0 otherwise.

The log likelihood contribution for an individual making $R$ transitions with state occupancy history $\left(i_{1}, i_{2}, i_{3}, \ldots, i_{R+1}\right)$ and transitions at ages

$\left(t^{1}, t^{2}, t^{3}, \ldots, t^{R}\right)$, time $z^{r}$ being the time spent in state $i_{r}$, conditional on observed and unobserved covariates is

$$
\begin{aligned}
L= & 1_{\left[t^{1}<c\right]} \log h_{i_{1} i_{2}}^{1}\left(z^{1} \mid x\left(z^{1}\right), v^{1}\right)-\sum_{j=1}^{k} I_{i_{1} j}^{1}\left(z^{1} \mid x\left(z^{1}\right), v^{1}\right) \\
& +1_{[R>1]} \sum_{r=2}^{R}\left(1_{\left[t^{r}<c\right]} \log h_{i_{r} i_{r+1}}^{2}\left(z^{r} \mid x\left(z^{r}\right), v^{2}\right)-\sum_{j=1}^{k} I_{i_{r} j}^{2}\left(z^{r} \mid x\left(z^{r}\right), v^{2}\right)\right)
\end{aligned}
$$

Note that the final term is only present when there is more than one transition, that all individuals start in state $i_{1}=\mathcal{H}$ and that all event histories are either right censored or end with $i_{R+1}=\mathcal{M}$.

The likelihood contribution conditional on observed covariates alone is the expectation of the likelihood contribution, given by exponentiating the previous expression, with respect to the joint distribution of $V^{1}$ and $V^{2}$.

\subsection{The conditional hazard functions}

A variety of patterns of duration dependence in the hazard function is accommodated by using a continuous piecewise linear functional form for the log hazard functions with two knots, as employed by Newman and McCulloch (1984). For $b>a$ let

$$
A(t, a, b)=\max (0, \min (t, b)-a)
$$


then the hazard function associated with passage from state $i$ to state $j$ at transition $r$ is

$h_{i j}^{r}(t)=\exp \left(x(t)^{\prime} \beta_{i j}^{r}+\alpha_{1 i j}^{r} A\left(t, 0, w_{1}\right)+\alpha_{2 i j}^{r} A\left(t, w_{1}, w_{2}\right)+\alpha_{3 i j}^{r} A\left(t, w_{2}, \infty\right)+\gamma^{r} v^{r}\right)$

in which $\gamma^{r}=1$ or $0, r \in\{1,2\}$, depending on whether allowance is made for across individual heterogeneity and if so whether a univariate or bivariate specification is employed. For example for $t>w_{2}$ the hazard function is

$$
h_{i j}^{r}(t)=\exp \left(x(t)^{\prime} \beta_{i j}^{r}+\alpha_{1 i j}^{r} w_{1}+\alpha_{2 i j}^{r}\left(w_{2}-w_{1}\right)+\alpha_{3 i j}^{r} t+\gamma^{r} v^{r}\right) .
$$

The knot locations, $w_{2}$ and $w_{1}$, are fixed a priori. For $r=1, w_{2}=15$ and $w_{1}=6$ (corresponding to ages 28 and 19). For $r=2, w_{2}=5$ and $w_{1}=3$. The three segment hazard functions can be everywhere increasing or decreasing, or bathtub or inverted bathtub shaped. If $\alpha_{3 i j}^{r}<0$ then the associated duration distribution is defective with a non-zero probability of no transition from state $i$ to state $j$ at transition $r$.

\subsection{Heterogeneity}

The joint distribution of $V^{1}$ and $V^{2}$ is modelled as a multivariate discrete distribution with two potential values for each variate: $v_{l}^{r}, r, l \in\{1,2\}$. The probability mass associated with the pair $\left\{v_{l}^{1}, v_{m}^{2}\right\}$ is $p_{l m}, l, m \in\{1,2\}$. The expected value of each $V^{r}$ is required to be zero implying

$$
\sum_{l=1}^{2} \sum_{m=1}^{2} v_{l}^{1} p_{l m}=\sum_{l=1}^{2} \sum_{m=1}^{2} v_{l}^{2} p_{m l}=0
$$

in addition to the restriction $\sum_{l=1}^{2} \sum_{m=1}^{2} p_{l m}=1$ and entails introduction of a constant "covariate" in $x(t)$. This is similar to the non-parametric mass point specification employed by Heckman and Singer (1984) but note that in this bivariate specification there is no search for a likelihood maximising number of mass points. Individuals with low values of $V^{1}$ and $V^{2}$ can be regarded as "stayers". Since "staying" may be a personal characteristic that persists through time it was felt essential to model $V^{1}$ and $V^{2}$ as potentially correlated variates. The results indicate a substantial positive correlation between these variates. 


\section{Data}

The NLSY provides evidence on transitions from home and into marriage. This is a panel data set of 12,686 persons aged 14-22 when first interviewed in 1979, who have been re-interviewed annually. This paper uses data through to, and including 1992, excluding individuals in the military sample. As interest is in the transitions from home, only those living in their parental home when first interviewed are examined ${ }^{5}$. The sample used contains 5,559 persons. The state "Living alone" is defined as living outside the parental home but not living in a stable partnership with an adult of the opposite gender. Because of the nature of the responses to the annual NLSY questionnaire dates of transitions are recorded to the nearest year. It is not known whether home and/or living expenses are provided by parents. To minimise misclassification of independent living the small numbers living in college dorms are defined to be living in the parental home. A period at home followed by a period alone whilst at college followed by another period at home is classified as a single spell at home.

Of this sample, 95\% had left the parental home by 1992. Mean age at leaving home for men is 21.77 years and for women 21.26 years. By 1992 $80.4 \%$ of men had married and 83.4 percent of women. There are considerable differences in these rates across races, as shown in Table 1. Rather more blacks than whites were still at home by 1992, those blacks leaving home doing so on average at a slightly later age than whites, and those blacks marrying doing so later on average than whites.

These rates mask considerable variation in the transitions between different states prior to marriage. Table 2 presents the various paths that individuals in the sample take between home and marriage. $\mathcal{H}$ denotes being at home, $\mathcal{A}$ living alone, and $\mathcal{M}$ marriage or cohabitation. All individuals in the sample used here begin at home. A transition labelled $\mathcal{H} \mathcal{M}$ represents a single transition during the sample period from home to marriage, while one labelled $\mathcal{H} \mathcal{A}$ represents a single transition from home to living alone. The

\footnotetext{
${ }^{5}$ There is a potential problem here. It is not possible to tell if individuals found in state $\mathcal{H}$ at first interview had previously been in other states and returned to $\mathcal{H}$ where they were first observed. However, of those in state $\mathcal{H}$ at 20 with an observed history going back to before age 16 , only $1.49 \%$ had histories involving departure from and return to $\mathcal{H}$ before age 20. All of this small number of persons experienced a $\mathcal{H} \mathcal{A H}$ transition rather than longer state histories, e.g. $\mathcal{H} \mathcal{A H} \mathcal{H} \mathcal{H}$. This evidence is taken to indicate that this is likely to be a trivial problem.
} 
path $\mathcal{H} \mathcal{A M}$ contains two transitions, the first from home to living alone, the second from living alone to marriage.

Table 2 shows the number of transitions that individuals make: $5 \%$ make no transitions, that is they stay in the parental home for the 12 year window in which they are observed, $29 \%$ make one transition, $52 \%$ make two transitions, $5 \%$ make three, and the rest make more. Table 2 also shows the number and types of transitions that end in marriage: $82 \%$ are married at the end of the period, $22 \%$ go straight from home to marriage, and $50 \%$ move first to live alone and then move into marriage. The remainder who marry have more complex moves into marriage. Table 2 also shows that leaving home is not an irreversible process: $15 \%$ of individuals return home at least once having moved from home to living alone for the first time.

The other columns of Table 2 break down these transitions by race $^{6}$ and gender. Patterns differ considerably between men and women and between races. In terms of number of transitions, black men and women are more likely not to make any transitions from the parental home: $8.8 \%$ and $9.4 \%$ of black men and women who started at home in 1979 were still at home when last interviewed, compared to $5.9 \%$ and $3.4 \%$ of Hispanic men and women and $3.5 \%$ and $1.9 \%$ of white men and women. Whites make more transitions than the other two groups. Within race, women are more likely than men to go from home directly to marriage, while across races this path has a higher relative frequency for Hispanics than either blacks or white. Black women are more likely than black men to move from home to living alone and stay there, while for the other races this pattern is more common amongst men. The net result of these complex moves is a lower marriage rate amongst blacks than whites or Hispanics.

The time constant covariates employed are the real income of the family ${ }^{7}$ with whom the respondent lived in 1979 and indicator variables identifying race (black, Hispanic, white), gender, the highest level of schooling attained by the respondent (a measure of the potential partner's view of the quality of the respondent in marriage), and an indicator distinguishing those who lived with both parents at age 14 which is interpreted as indicating predisposition towards the state of marriage ${ }^{8}$. The complexity of the estimation problem

\footnotetext{
${ }^{6}$ The category "white" includes non-whites who are not black or hispanic.

${ }^{7}$ To compute household income, the income data were cleaned following the procedure set out in Cole and Currie (1994).

${ }^{8}$ Another measure of taste for married life was considered, namely a measure of "traditional" family and gender role attitudes derived from the responses to the NLSY. As the
} 
Table 1: NLSY Sample Descriptive Statistics $(\mathrm{N}=5559)$

\begin{tabular}{lrrrrrr}
\hline & \multicolumn{2}{c}{ Whites } & \multicolumn{2}{c}{ Blacks } & \multicolumn{2}{c}{ Hispanics } \\
\cline { 2 - 6 } & Men & Women & Men & Women & Men & Women \\
\hline Mean age at marriage & 23.77 & 22.62 & 24.50 & 23.47 & 23.50 & 22.35 \\
Mean age at first transition & 21.60 & 21.03 & 22.13 & 21.92 & 21.81 & 21.07 \\
Percent not left home at age 30 & 3.70 & 2.17 & 9.78 & 9.93 & 7.08 & 3.56 \\
Percent not marrying at age 30 & 17.97 & 10.48 & 28.35 & 34.77 & 22.32 & 14.44 \\
Mean age first transition to alone & 21.51 & 20.98 & 21.96 & 21.91 & 21.68 & 21.14 \\
Mean time spent alone & 3.03 & 2.54 & 3.08 & 3.48 & 2.84 & 2.41 \\
\hline
\end{tabular}

limits the number of time varying covariates that can be included. The sample mean values of the covariates are given in Table 3.

Own resources is here measured by a single time varying covariate. Due to possible endogeneity problems of respondents' actual earnings we use predicted wage rates instead. Predicted wages are generated by estimation of a standard Mincerian earnings equation (Mincer (1974)) with data from the Current Population Survey (CPS). The predicted wages were then mapped into the NLSY sample. To derive predicted wages for the female sample we apply a two step procedure in order to control for the impact of selfselection into the labour force. The female is classified as participating in the labour force if hours worked during a week is positive. The covariates in these earnings equations include age, age squared, years of schooling, race, urban/rural dummy, year and state dummies. The estimated parameters conform quite closely to the literature. Wages are positively associated with age but at a declining rate, whereas the coefficient on years of education is within the standard range reported in the literature. Living in an urban area is associated with higher wages ${ }^{9}$.

\section{Results}

The results show that own resources and other income sources have a strong effect on the transitions, that there are significant differences between first and subsequent moves, and the importance of making allowance for across in-

estimates of the coefficient on this variable were always small and poorly defined, it was not used in producing the results reported here.

${ }^{9}$ The results from the estimated wage equations are available from the authors. 
Table 2: NLSY Transition Histories, Percentages

\begin{tabular}{|c|c|c|c|c|c|c|c|}
\hline \multirow[b]{2}{*}{ Transition type } & \multirow[t]{2}{*}{ All } & \multicolumn{2}{|c|}{ Whites } & \multicolumn{2}{|c|}{ Blacks } & \multicolumn{2}{|c|}{ Hispanics } \\
\hline & & Men & Women & Men & Women & Men & Women \\
\hline $\mathcal{H}$ & 4.73 & 3.5 & 1.9 & 8.8 & 9.4 & 5.8 & 3.4 \\
\hline $\mathcal{H} \mathcal{A}$ & 7.29 & 6.7 & 5.1 & 7.7 & 14.9 & 6.9 & 4.2 \\
\hline $\mathcal{H M}$ & 21.95 & 10.7 & 25.1 & 14.0 & 19.9 & 29.6 & 30.0 \\
\hline $\mathcal{H} \mathcal{A H}$ & 2.50 & 2.3 & 0.9 & 4.8 & 3.3 & 2.4 & 4.0 \\
\hline $\mathcal{H} \mathcal{A M}$ & 50.08 & 52.9 & 57.3 & 46.7 & 40.0 & 39.5 & 49.0 \\
\hline $\mathcal{H} \mathcal{A} \mathcal{H} \mathcal{A}$ & 2.75 & 3.1 & 1.2 & 1.7 & 3.4 & 3.4 & 1.7 \\
\hline $\mathcal{H} \mathcal{A} \mathcal{H} \mathcal{M}$ & 2.63 & 3.1 & 1.9 & 1.9 & 3.2 & 4.1 & 1.9 \\
\hline $\mathcal{H} \mathcal{A} \mathcal{H} \mathcal{A} \mathcal{H}$ & 0.53 & 0.7 & 0.2 & 0.0 & 1.4 & 0.2 & 0.0 \\
\hline $\mathcal{H} \mathcal{A H} \mathcal{H} \mathcal{M}$ & 6.39 & 8.0 & 5.6 & 4.4 & 8.2 & 6.2 & 4.4 \\
\hline $\mathrm{N}$ & 5559 & 1569 & 1565 & 716 & 765 & 466 & 478 \\
\hline
\end{tabular}

Table 3: Covariate values

\begin{tabular}{lccc}
\hline Covariate & Mean & Std. Error & $\mathrm{N}$ \\
\hline Female & 0.50 & 0.50 & 5559 \\
Black & 0.27 & 0.44 & 5559 \\
White & 0.56 & 0.49 & 5559 \\
High School Graduate & 0.43 & 0.49 & 5559 \\
College Graduate & 0.42 & 0.50 & 5559 \\
Lived with both parents at 14 & 0.70 & 0.45 & 5559 \\
Age in 1979 & 16.73 & 1.8 & 5559 \\
Family income in 1978 (\$1000) & 27.0 & 19.8 & 5559 \\
Predicted wages in 1976 & 2.68 & 0.60 & 5559 \\
Predicted wages in 1977 & 2.99 & 0.67 & 5559 \\
Predicted wages in 1978 & 3.34 & 0.75 & 5559 \\
Predicted wages in 1979 & 3.72 & 0.83 & 5559 \\
Predicted wages in 1980 & 3.82 & 0.81 & 5559 \\
Predicted wages in 1981 & 4.07 & 0.83 & 5426 \\
Predicted wages in 1982 & 4.33 & 0.85 & 5073 \\
Predicted wages in 1983 & 4.61 & 0.89 & 4642 \\
Predicted wages in 1984 & 4.82 & 0.95 & 4127 \\
Predicted wages in 1985 & 5.10 & 1.03 & 3614 \\
Predicted wages in 1986 & 5.26 & 1.08 & 3140 \\
Predicted wages in 1987 & 5.42 & 1.13 & 2659 \\
Predicted wages in 1988 & 5.55 & 1.18 & 2234 \\
Predicted wages in 1989 & 5.64 & 1.20 & 1911 \\
Predicted wages in 1990 & 5.83 & 1.25 & 1608 \\
Predicted wages in 1991 & 5.97 & 1.29 & 1378 \\
Predicted wages in 1992 & 5.92 & 1.28 & 1202 \\
\hline
\end{tabular}



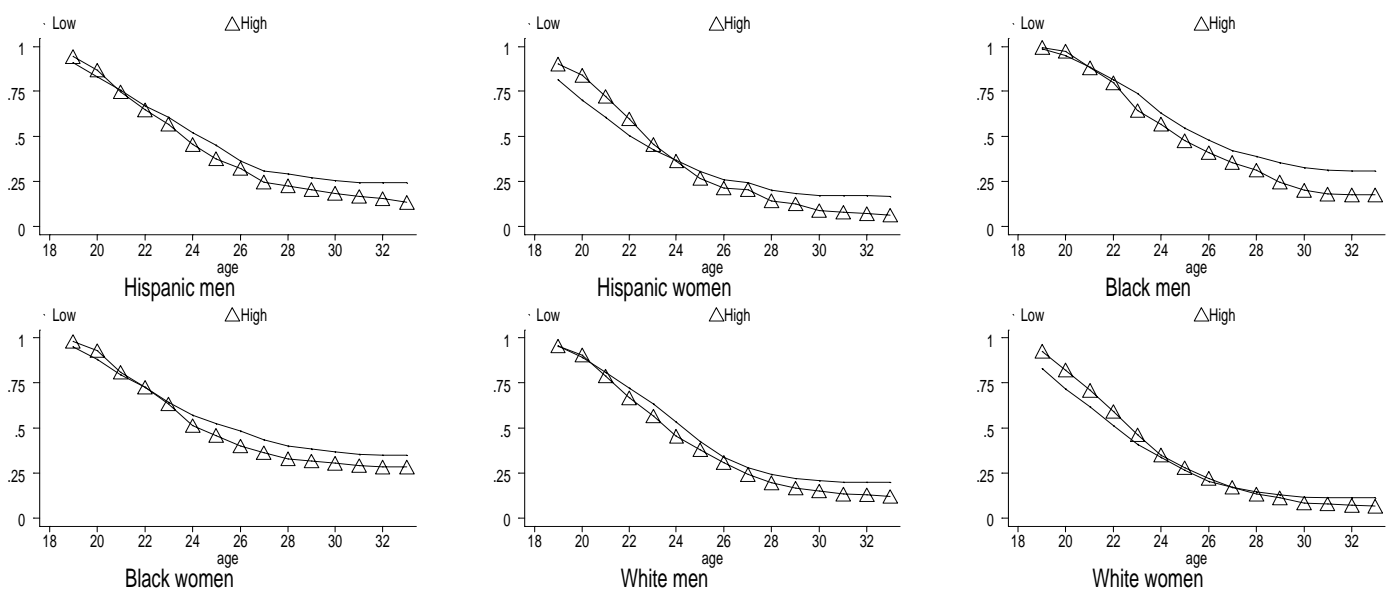

Figure 1: Sample mean age of marriage for different income groups

dividual heterogeneity. The model was estimated with and without the time varying predicted wages and with and without allowance for heterogeneity.

It is difficult to detect the earnings effects in an examination of the raw data. In Figure 1 the Kaplan Meier estimator of time to marriage from age 19 is plotted by race and gender for those with earnings in 1981 above and below median earnings. There is no very clear difference between those with higher and lower earnings. Similar patterns are found using earnings for 1979 through 1985. If individuals are grouped by their average annual earnings while in the sample, those with lower earnings marry sooner. On the other hand, if individuals are classified according to whether earnings at 19 are above or below the median for their gender-race group, the Kaplan Meier estimates suggest that those with higher earnings marry sooner.

The econometric modelling gives rather clearer results. The coefficient estimates show that both predicted wages and parental home income are 
important determinants of the transitions from home to living independently and to marriage. In general higher own resources increases the speed at which transitions out of home are made, while higher parental resources delays these transitions.

Table 4 provides results from the preferred model which includes (timevarying) predicted wages and correlated heterogeneity on the first and subsequent transitions. The upper part of the table shows the parameter estimates of the first transitions, whereas the lower part shows estimates of subsequent transitions. The estimated masspoints and their associated probabilities are reported at the bottom of the table. The coefficient estimates are in general precisely estimated for the first move, and in many cases well defined for subsequent moves. They show the following.

Demography is an important determinant of transition behaviour. Women leave home significantly quicker than men to both destinations. Once alone, they return home significantly less fast, but leave to marriage faster. If they do return home, they are more likely to leave faster the second time round although the difference between the genders is not significant for the transition to marriage. Blacks leave home and move to marriage slower than either Hispanics (the omitted group) or whites in first and any subsequent moves. Whites are more likely to leave home to live alone than to marry than blacks or Hispanics. Race and gender matter conditional on income.

Educational attainment affects the first transition out of the parental home, but has no significant impact on subsequent moves. The higher the final educational status attained, the later individuals leave home. The delay is greater for the destination of marriage than for independent living. The demographic and educational attainment covariate patterns are robust to the exclusion of both family income and own earnings. Because wages are correlated with gender and educational attainment, the effect of omitting predicted wage is to reduce the absolute magnitude of the parameter estimates for gender and educational attainment ${ }^{10}$.

The circumstances of the family home affect the transitions. Those who lived with both parents at 14 are less likely to leave home initially either to live alone or to marry, although conditional on making a transition to living alone living arrangements at 14 have no effect on subsequent transitions. Higher family income significantly delays leaving home for the first time as

\footnotetext{
${ }^{10}$ These and other tests of the model not tabled here are available from the authors on request.
} 
well as subsequent transitions, though the effect is weaker on these second and subsequent transitions.

The respondent's own economic resources matter. Higher predicted wages are significantly associated with an increase in the rate at which individuals leave home to either destination, an increase in the rate at which individuals once alone form partnerships, as well as a weak positive effect on returning home, and an increase in the rate at which individuals leave home if they have returned after their initial departure.

The coefficients of baseline hazards for the first transition processes given in table 4 show that these are inverse $U$ shaped, rising sharply to age 19, rising less quickly up to age 28 , and falling thereafter. Since there is control for heterogeneity it seems likely that there is genuine duration dependence. For all types of subsequent transition, the hazard rises to age 19, falls strongly between the ages of 19 and 28, but generally insignificant after 28. Although there are differences between the segments of the hazard for the subsequent transitions, these are less marked than for the first move, and the hazard is closer to being flat.

The heterogeneity mass point estimates, and the associated estimated probabilities are shown at the bottom of table 4. The estimates suggest that around 51 percent of the sample were movers on both the first and the subsequent transitions, 12 percent movers on the first transition and stayers on the second, 11 percent were stayers on the first transition and movers on the second, and the remaining 26 percent stayers for both. The impact of controlling for heterogeneity can be evaluated by comparing this to Table 6 which presents the model estimated without heterogeneity. The effect is to increase the absolute magnitude of the parameter estimates and the precision with which they are estimated. However, the shape of the baseline hazard is relatively unaffected by allowing for heterogeneity, conditional on inclusion of predicted wages in the estimated model ${ }^{11}$.

The results to be discussed now indicate the importance of allowing for both time varying wages and heterogeneity. Table 6 allows for time varying earnings, but no heterogeneity. Table 7 presents the results estimated with-

\footnotetext{
${ }^{11}$ A simpler specification of unobserved heterogeneity using a univariate specification with $V^{2}$ absent from the model was also estimated (see section 4.4). A version with three points of support produced masspoint values equal to $-5.75,-1.33$ and 1.23 with probabilities of $0.08,0.26$ and 0.66 respectively, whereas a model with only two points of support produced mass points equal to -1.54 and 0.38 with probabilities 0.20 and 0.80 , respectively.
} 
out either time varying earnings and heterogeneity. Comparison of Tables 7 and 4 indicates the effect of allowing for both own earnings and heterogeneity is to increase the absolute magnitude of the parameter estimates and the precision with which they are estimated, while the baseline hazard remains unchanged. If the model is reestimated without predicted wages but allowing for heterogeneity (available from the authors), the baseline hazard is estimated as being upward sloping. Average earnings increase over time, and the effect of earnings is to increase the rate at which individuals leave home and marry. So not conditioning on predicted wages, but allowing for heterogeneity, masks the duration effect apparent in Table $4^{12}$.

In order to explore the effect of endogeneity of own earnings on the parameter estimates we re-estimated the model using annual own earnings instead of the predicted wage levels. These results (obtainable from the authors) show that the impact on the coefficients in the first transitions is small, but more noticeable for the subsequent transitions $\mathcal{H} \rightarrow \mathcal{A}$ and $\mathcal{A} \rightarrow \mathcal{H}$. In the latter case we find the earnings coefficients to be negative and insignificant. Using actual own earnings has also an impact on the parameters associated with unobserved heterogeneity. In particular we observe a shift from the "stayer, stayer" group to the "mover, stayer" group, with new probability values of 0.29 and 0.088 respectively.

A small proportion of individuals in the NLSY make their first transition to either independent living or marriage prior to 1979. These individuals are excluded from the sample used in the estimation. Since this might generate a selection bias we re-estimate the model reported in table 4 with a reduced sample consisting of individuals aged 14 to 17 in 1979. These results are reported in table 7 . They show a continued strong effect of predicted wages on first transitions to independent living and marriage. For the subsequent transitions the effects are even stronger. The family income is negatively associated with all transitions. Coming from an intact family has little effect

\footnotetext{
${ }^{12}$ The model in table 5 constrains the effects of the two measures of marriage quality - predicted wages and education - to be the equal for men and women. Earlier research has found that these measures have different effects for the two genders. The model of Table 4 was re-estimated separately for men and women. The overall shape of the hazard is similar for both men and women. But there are some significant differences in the coefficient estimates between the genders. Education appears less important for men. Higher education delays time to marriage but not the transition to living alone for men, while for women it delays both the transition to independent living and that to marriage. The earnings effects for men and women have the same signs across all transitions, but the effect of predicted wages for women is larger in absolute terms in all transitions.
} 
on the transition to independent living, which is in contrast to the full sample results, whereas the other parameter estimates are very similar, including the pattern of unobserved heterogeneity. This suggest that sample selection is not a big problem in this case.

The results presented so far have given no indication of the goodness of fit of the model. This was assessed as follows. For each individual from the original sample 5 replications were created, each with the same values of the sampled individual's covariates. Using the parameter estimates from Table 5 synthetic histories were simulated for each replication, giving a set of simulated histories which are for individuals which 'match' the original sample. Marginal statistics from these synthetic histories are given in Tables 8 and 9 . These can be compared, formally and informally, to the sample analogues in Tables 1 and 2. A formal test of no differences between mean age of marriage with race-gender groups between the actual and synthetic sample (the test correcting for censoring) did not reject equality of all 6 pairs of means. Less formal comparison of the Tables 2 and 9 indicates, for the most part, a close correspondence between the synthetic transition histories and the original sample. For all comparisons the distribution of transition types in the actual and synthetic data differs by at most three percentage points. Within race-gender groups, the largest difference between the replicated and actual samples is for Hispanic men for transition type $\mathcal{H} \mathcal{A M}$, where the percentages with this transition in the replicated sample is about $10 \%$ points higher but Hispanic men are the smallest group in the data, so a poorer fit for this group might be expected. The percentage of black men making this transition is also overestimated.

In summary, the coefficient estimates show that both predicted wages and parental home income are important determinants of the transitions from home to living independently and to marriage. In general higher wages increases the speed at which transitions out of home are made, while higher parental resources delays these transitions. But the model is very complex and so the net effect of income on the transitions is difficult to assess from the parameter estimates. In order to gain a clearer view of the impact of own earnings on the transition process the estimated model was simulated as described now. 
Table 4: Time varying predicted wages and correlated bivariate masspoints

\begin{tabular}{|c|c|c|c|c|}
\hline \multirow[t]{2}{*}{ Variables } & \multicolumn{2}{|c|}{$\overline{\mathcal{H} \rightarrow \mathcal{A}_{F}}$} & \multicolumn{2}{|c|}{$\overline{\mathcal{H} \rightarrow \mathcal{M}_{F}}$} \\
\hline & Coef. & S.E. & Coef. & S.E. \\
\hline INTERCEPT & -5.532 & $(0.213)$ & -7.295 & $(0.419)$ \\
\hline FEMALE & 0.333 & $(0.038)$ & 0.772 & $(0.068)$ \\
\hline BLACK & -0.029 & $(0.062)$ & -0.812 & $(0.103)$ \\
\hline WHITE & 0.422 & $(0.053)$ & 0.002 & $(0.079)$ \\
\hline HIGH SCHOOL & -0.191 & $(0.066)$ & -0.412 & $(0.094)$ \\
\hline HIGHER ED. & -0.382 & $(0.073)$ & -1.238 & $(0.121)$ \\
\hline INTACT FAM. AT 14 & -0.464 & $(0.073)$ & -0.167 & $(0.073)$ \\
\hline FAMILY INC. 78 & -0.662 & $(0.018)$ & -0.615 & $(0.028)$ \\
\hline PREDICTED WAGE & 1.314 & $(0.027)$ & 1.117 & $(0.058)$ \\
\hline A1 & 7.903 & $(0.357)$ & 10.169 & $(0.725)$ \\
\hline $\mathrm{A} 2$ & -0.632 & $(0.147)$ & 0.338 & $(0.219)$ \\
\hline \multirow[t]{2}{*}{ A3 } & -7.317 & $(0.728)$ & -8.301 & $(1.387)$ \\
\hline & \multicolumn{2}{|c|}{$\overline{\mathcal{H} \rightarrow \mathcal{A}_{S}}$} & \multicolumn{2}{|c|}{$\overline{\mathcal{H} \rightarrow \mathcal{M}_{S}}$} \\
\hline INTERCEPT & 0.249 & $(0.258)$ & -0.151 & $(0.506)$ \\
\hline FEMALE & 0.267 & $(0.088)$ & 0.251 & $(0.170)$ \\
\hline BLACK & -0.141 & $(0.125)$ & -0.436 & $(0.247)$ \\
\hline WHITE & 0.384 & $(0.119)$ & 0.584 & $(0.226)$ \\
\hline FAMILY IN. 78 & -0.187 & $(0.048)$ & -0.610 & $(0.103)$ \\
\hline PREDICTED WAGE & 0.232 & $(0.048)$ & 0.651 & $(0.011)$ \\
\hline A1 & 4.927 & $(0.593)$ & 3.304 & $(1.239)$ \\
\hline $\mathrm{A} 2$ & -4.098 & $(1.722)$ & -4.098 & $(1.722)$ \\
\hline \multirow[t]{2}{*}{ A3 } & -0.974 & $(1.187)$ & 1.204 & $(1.446)$ \\
\hline & \multicolumn{2}{|c|}{$\mathcal{A} \rightarrow \mathcal{H}$} & \multicolumn{2}{|c|}{$\mathcal{A} \rightarrow \mathcal{M}$} \\
\hline INTERCEPT & 0.463 & $(0.222)$ & 1.832 & $(0.124)$ \\
\hline FEMALE & -0.269 & $(0.075)$ & 0.166 & $(0.041)$ \\
\hline BLACK & -0.360 & $(0.113)$ & -0.673 & $(0.066)$ \\
\hline WHITE & -0.289 & $(0.103)$ & 0.072 & $(0.057)$ \\
\hline FAMILY INC. 78 & -0.215 & $(0.035)$ & -0.422 & $(0.021)$ \\
\hline PREDICTED WAGE & 0.160 & $(0.039)$ & 0.387 & $(0.022)$ \\
\hline A1 & 3.983 & $(0.497)$ & 2.698 & $(0.326)$ \\
\hline A2 & -8.784 & $(0.883)$ & -4.111 & $(0.440)$ \\
\hline A3 & 0.841 & $(0.818)$ & 0.031 & $(0.352)$ \\
\hline MASSPT. Va1: & $\overline{0.701}$ & & OB 11: & 0.508 \\
\hline MASSPT. Vb1: & 0.426 & & OB 12: & 0.124 \\
\hline MASSPT. Va2: & -1.127 & & OB 21: & 0.106 \\
\hline MASSPT. Vab: & -0.732 & & OB 22: & 0.261 \\
\hline $\begin{array}{l}\log \mathrm{L} . \\
\mathrm{N}\end{array}$ & $\begin{array}{c}-4152.5 \\
5559 \\
\end{array}$ & & & \\
\hline
\end{tabular}


Table 5: Time varying predicted wages without controls for unobserved heterogeneity

\begin{tabular}{|c|c|c|c|c|}
\hline Variables & \multicolumn{2}{|c|}{$\mathcal{H} \rightarrow \mathcal{A}_{F}$} & \multicolumn{2}{|c|}{$\mathcal{H} \rightarrow \mathcal{M}_{F}$} \\
\hline & Coef. & S.E. & Coef. & S.E. \\
\hline INTERCEPT & -5.122 & $(0.206)$ & -5.847 & $(0.425)$ \\
\hline FEMALE & 0.204 & $(0.032)$ & 0.519 & $(0.064)$ \\
\hline BLACK & 0.039 & $(0.051)$ & -0.801 & $(0.092)$ \\
\hline WHITE & 0.330 & $(0.042)$ & -0.105 & $(0.069)$ \\
\hline HIGH SCHOOL & -0.120 & $(0.051)$ & -0.194 & $(0.086)$ \\
\hline HIGHER ED. & -0.132 & $(0.058)$ & -0.621 & $(0.117)$ \\
\hline INTACT FAM. AT 14 & -0.297 & $(0.032)$ & 0.009 & $(0.067)$ \\
\hline FAMILY INC. 78 & -0.555 & $(0.019)$ & -0.781 & $(0.047)$ \\
\hline PREDICTED WAGE & 1.057 & $(0.067)$ & 1.082 & $(0.066)$ \\
\hline A1 & 7.975 & $(0.342)$ & 9.452 & $(0.712)$ \\
\hline A2 & -1.767 & $(0.100)$ & -1.267 & $(0.189)$ \\
\hline A3 & -5.491 & $(0.747)$ & 6.339 & $(1.380)$ \\
\hline & \multicolumn{2}{|c|}{$\mathcal{H} \rightarrow \mathcal{A}_{S}$} & \multicolumn{2}{|c|}{$\overline{\mathcal{H} \rightarrow \mathcal{M}_{S}}$} \\
\hline INTERCEPT & 0.333 & $(0.247)$ & -0.102 & $(0.479)$ \\
\hline FEMALE & 0.144 & $(0.080)$ & 0.119 & $(0.164)$ \\
\hline BLACK & 0.003 & $(0.114)$ & -0.288 & $(0.240)$ \\
\hline WHITE & 0.359 & $(0.109)$ & 0.536 & $(0.218)$ \\
\hline FAMILY IN. 78 & -0.057 & $(0.044)$ & -0.449 & $(0.097)$ \\
\hline PREDICTED WAGE & 0.055 & $(0.043)$ & 0.450 & $(0.096)$ \\
\hline A1 & 4.530 & $(0.589)$ & 2.869 & $(1.233)$ \\
\hline A2 & -6.100 & $(0.982)$ & -4.484 & (1.681) \\
\hline \multirow[t]{2}{*}{ A3 } & -1.105 & $(1.195)$ & 1.126 & $(1.365)$ \\
\hline & \multicolumn{2}{|c|}{$\mathcal{A} \rightarrow \mathcal{H}$} & \multicolumn{2}{|c|}{$\mathcal{A} \rightarrow \mathcal{M}$} \\
\hline INTERCEPT & 0.501 & $(0.207)$ & 1.826 & $(0.109)$ \\
\hline FEMALE & -0.354 & $(0.069)$ & 0.090 & $(0.035)$ \\
\hline BLACK & -0.218 & $(0.104)$ & -0.527 & $(0.056)$ \\
\hline WHITE & -0.291 & $(0.095)$ & 0.068 & $(0.048)$ \\
\hline FAMILY INC. 78 & -0.106 & $(0.033)$ & -0.293 & $(0.018)$ \\
\hline PREDICTED WAGE & 0.007 & $(0.036)$ & 0.220 & $(0.017)$ \\
\hline A1 & 3.283 & $(0.485)$ & 1.865 & $(0.294)$ \\
\hline A2 & -8.984 & $(0.863)$ & -4.257 & $(0.412)$ \\
\hline A3 & 0.538 & $(0.812)$ & -0.243 & $(0.323)$ \\
\hline $\begin{array}{l}\log L . \\
N\end{array}$ & $\begin{array}{c}4368.7 \\
5559\end{array}$ & & & \\
\hline
\end{tabular}


Table 6: Without time varying earnings and no control for unobserved heterogeneity

\begin{tabular}{|c|c|c|c|c|}
\hline \multirow[t]{2}{*}{ Variables } & \multicolumn{2}{|c|}{$\overline{\overline{\mathcal{H}} \rightarrow \mathcal{A}_{F}}$} & \multicolumn{2}{|c|}{$\overline{\mathcal{H} \rightarrow \mathcal{M}_{F}}$} \\
\hline & Coef. & S.E. & Coef. & S.E. \\
\hline INTERCEPT & -6.085 & $(0.194)$ & -7.729 & $(0.394)$ \\
\hline FEMALE & 0.134 & $(0.031)$ & 0.555 & $(0.058)$ \\
\hline BLACK & -0.217 & $(0.050)$ & -0.927 & $(0.086)$ \\
\hline WHITE & 0.306 & $(0.045)$ & -0.102 & $(0.070)$ \\
\hline HIGH SCHOOL & -0.001 & $(0.046)$ & -0.222 & $(0.076)$ \\
\hline HIGHER ED. & -0.147 & $(0.050)$ & -0.971 & $(0.087)$ \\
\hline INTACT FAM. AT 14 & -0.297 & $(0.035)$ & -0.009 & $(0.068)$ \\
\hline FAMILY INC. 78 & -0.409 & $(0.099)$ & -0.562 & $(0.168)$ \\
\hline A1 & 11.337 & $(0.339)$ & 12.718 & $(0.692)$ \\
\hline $\mathrm{A} 2$ & 0.721 & $(0.069)$ & 0.939 & $(0.131)$ \\
\hline \multirow[t]{2}{*}{ A3 } & -3.525 & $(0.631)$ & -2.089 & $(0.872)$ \\
\hline & \multicolumn{2}{|c|}{$\mathcal{H} \rightarrow \mathcal{A}_{S}$} & \multicolumn{2}{|c|}{$\mathcal{H} \rightarrow \mathcal{M}_{S}$} \\
\hline INTERCEPT & 0.176 & $(0.148)$ & -0.959 & $(0.327)$ \\
\hline FEMALE & 0.142 & $(0.081)$ & 0.108 & $(0.165)$ \\
\hline BLACK & 0.017 & $(0.113)$ & -0.233 & $(0.245)$ \\
\hline WHITE & 0.320 & $(0.110)$ & 0.407 & $(0.225)$ \\
\hline FAMILY INC. 78 & 0.108 & $(0.204)$ & -0.474 & $(0.434)$ \\
\hline A1 & 4.650 & $(0.579)$ & 3.721 & $(1.208)$ \\
\hline $\mathrm{A} 2$ & -5.967 & $(0.972)$ & -3.590 & $(1.648)$ \\
\hline \multirow[t]{2}{*}{ A3 } & -1.059 & $(1.189)$ & 1.543 & $(1.368)$ \\
\hline & \multicolumn{2}{|c|}{$\mathcal{A} \rightarrow \mathcal{H}$} & \multicolumn{2}{|c|}{$\mathcal{A} \rightarrow \mathcal{M}$} \\
\hline INTERCEPT & -0.070 & $(0.119)$ & 0.831 & $(0.071)$ \\
\hline FEMALE & -0.313 & $(0.069)$ & 0.158 & $(0.036)$ \\
\hline BLACK & -0.135 & $(0.101)$ & -0.385 & $(0.057)$ \\
\hline WHITE & -0.281 & $(0.095)$ & 0.033 & $(0.051)$ \\
\hline FAMILY INC. 78 & -0.300 & $(0.175)$ & -0.254 & $(0.093)$ \\
\hline $\mathrm{A} 1$ & 3.189 & $(0.475)$ & 2.126 & $(0.291)$ \\
\hline $\mathrm{A} 2$ & -8.970 & $(0.861)$ & -3.703 & $(0.411)$ \\
\hline A3 & 0.487 & $(0.808)$ & 0.082 & $(0.326)$ \\
\hline $\begin{array}{l}\text { Log L. } \\
\text { N }\end{array}$ & $\begin{array}{c}-5031.1 \\
5559\end{array}$ & & & \\
\hline
\end{tabular}


Table 7: Time varying predicted wages and correlated bivariate masspoints, excluding 18 - 20 year olds in 1979

\begin{tabular}{|c|c|c|c|c|}
\hline Variables & \multicolumn{2}{|c|}{$\overline{\mathcal{H}} \rightarrow \mathcal{A}_{F}$} & \multicolumn{2}{|c|}{$\overline{\mathcal{H}} \rightarrow \mathcal{M}_{F}$} \\
\hline & Coef. & S.E. & Coef. & S.E. \\
\hline INTERCEPT & -6.154 & $(0.238)$ & -7.991 & $(0.468)$ \\
\hline FEMALE & 0.473 & $(0.049)$ & 0.958 & $(0.087)$ \\
\hline BLACK & -0.005 & $(0.073)$ & -0.778 & $(0.131)$ \\
\hline WHITE & 0.400 & $(0.061)$ & -0.042 & $(0.098)$ \\
\hline HIGH SCHOOL & -0.260 & $(0.078)$ & -0.627 & $(0.111)$ \\
\hline HIGHER ED. & -0.752 & $(0.086)$ & -0.813 & $(0.149)$ \\
\hline INTACT FAM. AT 14 & -0.436 & $(0.048)$ & -0.119 & $(0.090)$ \\
\hline FAMILY INC. 78 & -0.665 & $(0.023)$ & -0.559 & $(0.035)$ \\
\hline PREDICTED WAGE & 1.513 & $(0.033)$ & 1.209 & $(0.079)$ \\
\hline A1 & 8.44 & $(0.394)$ & 11.075 & $(0.797)$ \\
\hline A2 & -1.571 & $(0.172)$ & -0.528 & $(0.299)$ \\
\hline \multirow[t]{2}{*}{ A3 } & -21.210 & $(3.642)$ & -20.560 & $(7.295)$ \\
\hline & \multicolumn{2}{|c|}{$\overline{\mathcal{H} \rightarrow \mathcal{A}_{S}}$} & \multicolumn{2}{|c|}{$\mathcal{H} \rightarrow \mathcal{M}_{S}$} \\
\hline INTERCEPT & -0.175 & $(0.321)$ & -0.843 & $(0.667)$ \\
\hline FEMALE & 0.541 & $(0.112)$ & 0.454 & $(0.225)$ \\
\hline BLACK & 0.046 & $(0.152)$ & -0.063 & $(0.307)$ \\
\hline WHITE & 0.616 & $(0.147)$ & 0.846 & $(0.287)$ \\
\hline FAMILY IN. 78 & -0.619 & $(0.118)$ & -0.263 & $(0.042)$ \\
\hline PREDICTED WAGE & 0.409 & $(0.065)$ & 0.851 & $(0.133)$ \\
\hline$\overline{\mathrm{A} 1}$ & 5.350 & $(0.713)$ & 2.405 & $(1.716)$ \\
\hline A2 & -8.107 & $(1.307)$ & -1.561 & $(2.060)$ \\
\hline \multirow[t]{2}{*}{ A3 } & 1.065 & $(1.359)$ & 0.743 & $(1.868)$ \\
\hline & \multicolumn{2}{|c|}{$\overrightarrow{\mathcal{A} \rightarrow \mathcal{H}}$} & \multicolumn{2}{|c|}{$\mathcal{A} \rightarrow \mathcal{M}$} \\
\hline INTERCEPT & 0.339 & $(0.272)$ & 1.539 & $(0.155)$ \\
\hline FEMALE & -0.209 & $(0.093)$ & 0.257 & $(0.051)$ \\
\hline BLACK & -0.341 & $(0.138)$ & -0.688 & $(0.082)$ \\
\hline WHITE & -0.278 & $(0.125)$ & 0.076 & $(0.070)$ \\
\hline FAMILY INC. 78 & -0.262 & $(0.042)$ & -0.444 & $(0.025)$ \\
\hline PREDICTED WAGE & 0.319 & $(0.057)$ & 0.542 & $(0.032)$ \\
\hline A1 & 3.700 & $(0.614)$ & 2.635 & $(0.403)$ \\
\hline $\mathrm{A} 2$ & -8.900 & $(1.093)$ & -4.378 & $(0.546)$ \\
\hline A3 & 1.447 & $(1.139)$ & 0.571 & $(0.484)$ \\
\hline MASSPT. Va1: & $\overline{\overline{1.110}}$ & & $\overline{\text { 2OB 11: }}$ & 0.420 \\
\hline MASSPT. Vb1: & 0.477 & & 2OB 12: & 0.067 \\
\hline MASSPT. Va2: & -1.054 & & 2OB 21: & 0.182 \\
\hline MASSPT. Vab: & -0.724 & & 2OB 22: & 0.331 \\
\hline $\begin{array}{l}\log \mathrm{L} . \\
\mathrm{N}\end{array}$ & $\begin{array}{c}-2328.06 \\
5559\end{array}$ & & & \\
\hline
\end{tabular}




\section{Implications of the results: simulations}

In this Section the estimated effect of different wage level paths on patterns of living arrangements is explored using simulations of the fitted model. In each simulation 33354 synthetic event histories are simulated using the fitted model with a bivariate specification of across individual heterogeneity (Table 4). For each synthetic individual a pair of values, $v^{1}$ and $v^{2}$ of $V^{1}$ and $V^{2}$ are sampled from their estimated bivariate distribution ${ }^{13}$. Then the estimated transition process conditional on these values is simulated until marriage or a maximum of fourteen years. The resulting set of synthetic histories can be processed to produce interesting statistics which would be difficult to obtain analytically from the estimated model (e.g. time to marriage) and to produce comparisons of predicted values with sample marginal statistics.

Three time paths were chosen for the time varying predicted wages. The first path is set by subtracting 50 percent from the original wage level, the second path is the original level, and the third path is obtained by adding 50 percent to the original level.

Tables 10 and 11 present a summary of the impact of differences in predicted wage paths on simulated transitions for white and blacks respectively, males and females separately. The columns labelled $-50 \%$ indicate the effect of reducing the predicted wage by 50 percent, 0 indicates the original level, and $+50 \%$ indicates an increase of 50 percent. The Tables show that the effect of higher earnings is to reduce the median age at marriage, reduce the age at which individuals make their first transition, decrease the probability of never leaving home, and decrease the time spent living alone for both men and women.

The results in Table 10 for white men show if predicted wages are reduced, median age at marriage is 23.57 . If wages are at the original level, median age of marriage is 23.28 , and if wages are increased by 50 percent then median age of marriage is 22.83 . The same figures for women are $22.78,22.43$, and 22.17 respectively. These differences are not large. However, looking at the proportion not married reveals a much greater impact of earnings differences: for white men, the proportion not married is more than twice as high at the low wage level (17.04\%) compared to the low wage level (8.55\%). For white women, the results show the same pattern: $9.20 \%$ at the low wage level $6.21 \%$ at the high wage level. This reflects the fact that predicted differences

\footnotetext{
${ }^{13}$ Details are available from the authors.
} 
Table 8: Simulation data: Summary statistics (33354 replications)

\begin{tabular}{lcccccc}
\hline & \multicolumn{2}{c}{ Whites } & \multicolumn{2}{c}{ Blacks } & \multicolumn{2}{c}{ Hispanics } \\
\cline { 2 - 7 } & Men & Women & Men & Women & Men & Women \\
\hline Mean age at marriage & 23.49 & 22.60 & 24.51 & 23.79 & 23.35 & 22.69 \\
Mean age first transition & 21.87 & 21.18 & 22.77 & 21.97 & 21.96 & 21.40 \\
Percent not left home by age 30 & 5.85 & 3.77 & 9.84 & 7.23 & 6.63 & 5.31 \\
Percent not marrying by age 30 & 18.75 & 10.91 & 34.06 & 24.11 & 21.08 & 14.83 \\
Mean age first transition to alone & 21.86 & 21.04 & 22.63 & 21.99 & 21.86 & 21.32 \\
Mean time spent alone & 2.40 & 2.26 & 3.01 & 2.89 & 2.56 & 2.38 \\
\hline
\end{tabular}

in marriage rates between low and high earnings individuals increase with age (see Figure 2, described below). The other rows of the table show a similar effect of wages on transitions out of home, and into marriage. The higher are predicted wages the fewer individuals are predicted never to leave home, and the fewer are predicted never to marry. The fall in age at marriage is greater than the fall in the age at which individuals leave home, so the amount of time spent alone also falls with wages.

Table 11 shows that the same results hold for simulations of black individuals. Age of marriage falls with income, albeit from a later age than for whites. Comparison across the columns indicates that the impact of higher earnings is to increase the rate at which transitions away from home and into marriage are made. Again, the percentage of people never marrying is considerably higher at lower wage levels.

These tables show summary statistics, so do not indicate the impact of changes in income on the whole distribution. Figure 2 plots the survivor functions (age at marriage) for simulated individuals with wages set to -50 percent and +50 percent of the original levels. These functions are graphed for each race-gender group. The plots show clearly that the impact of higher earnings is to increase the probability of entering marriage at all ages for all race-gender groups. The largest impact of an increase in wages from the lower level $(-50 \%)$ to the upper level $(+50 \%)$ on the survivor function is for black men, particularly at older ages. The smallest impact is amongst white women. The figure also shows the differences and similarities in the simulated survivor function across races and genders. The probability of becoming married for black men, even at the higher level of wages, is noticeably lower than that of all the other groups. 
Table 9: Simulated transition histories, Percentages

\begin{tabular}{lccccccc}
\hline & \multicolumn{4}{c}{ All } & \multicolumn{2}{c}{ Whites } & \multicolumn{2}{c}{ Blacks } & \multicolumn{2}{c}{ Hispanics } \\
\cline { 2 - 8 } Transition type & & Men & Women & Men & Women & Men & Women \\
\hline $\mathcal{H}$ & 6.4 & 5.4 & 3.5 & 5.2 & 8.0 & 5.2 & 5.8 \\
$\mathcal{H} \mathcal{A}$ & 5.0 & 4.8 & 3.6 & 4.6 & 6.6 & 4.6 & 3.7 \\
$\mathcal{H} \mathcal{M}$ & 19.4 & 15.7 & 22.9 & 23.3 & 16.7 & 23.3 & 31.3 \\
$\mathcal{H} \mathcal{A H}$ & 0.6 & 0.4 & 0.2 & 0.6 & 0.9 & 0.6 & 0.5 \\
$\mathcal{H} \mathcal{A} \mathcal{M}$ & 51.9 & 55.9 & 56.5 & 47.4 & 49.9 & 47.4 & 45.0 \\
$\mathcal{H} \mathcal{A H} \mathcal{H}$ & 0.8 & 0.6 & 0.5 & 0.6 & 1.2 & 0.6 & 0.5 \\
$\mathcal{H} \mathcal{A} \mathcal{H} \mathcal{M}$ & 3.9 & 4.6 & 2.8 & 5.3 & 3.6 & 5.3 & 2.9 \\
$\mathcal{H} \mathcal{A H} \mathcal{H} \mathcal{H}$ & 0.2 & 0.1 & 0.0 & 0.2 & 0.3 & 0.2 & 0.2 \\
$\mathcal{H} \mathcal{A H \mathcal { M }}$ & 6.6 & 6.7 & 6.6 & 5.7 & 7.5 & 5.7 & 5.1 \\
\hline
\end{tabular}

Table 10: The effect of predicted wages on simulated transitions: Whites

\begin{tabular}{lcccccc}
\hline & \multicolumn{5}{c}{ Whites } \\
\cline { 2 - 7 } & $-50 \%$ & 0 & $+50 \%$ & $-50 \%$ & 0 & $+50 \%$ \\
\hline Median age at marriage & 23.57 & 23.28 & 22.83 & 22.78 & 22.43 & 22.17 \\
Q25 age at marriage & 21.61 & 21.41 & 21.12 & 20.83 & 20.68 & 20.41 \\
Q75 age at marriage & 25.63 & 25.28 & 24.81 & 24.89 & 24.61 & 24.09 \\
Median age at first transition & 21.85 & 21.58 & 21.36 & 21.15 & 20.87 & 20.65 \\
Percent never leave home & 5.23 & 3.42 & 2.07 & 4.13 & 1.62 & 1.07 \\
Percent not marrying & 17.04 & 12.18 & 8.55 & 9.20 & 7.11 & 6.21 \\
Median age first trans to alone & 21.75 & 21.52 & 21.27 & 20.97 & 20.77 & 20.46 \\
Median time spent alone & 2.75 & 2.55 & 2.28 & 2.52 & 2.39 & 2.31 \\
\hline
\end{tabular}

Table 11: The effect of predicted wages on simulated transitions: Blacks

\begin{tabular}{lcccccc}
\hline & \multicolumn{5}{c}{ Blacks } \\
\cline { 2 - 7 } & $-50 \%$ & 0 & $+50 \%$ & $-50 \%$ & 0 & $+50 \%$ \\
\hline Median age at marriage & 24.65 & 24.40 & 24.16 & 23.83 & 23.59 & 23.50 \\
Q25 age at marriage & 23.02 & 22.85 & 22.64 & 22.30 & 22.13 & 21.95 \\
Q75 age at marriage & 26.77 & 26.46 & 26.20 & 26.24 & 25.98 & 25.59 \\
Median age at first transition & 22.87 & 22.69 & 22.46 & 22.05 & 21.85 & 21.58 \\
Percent never leave home & 10.35 & 7.90 & 3.71 & 6.36 & 5.26 & 2.01 \\
Percent not marrying & 38.20 & 31.69 & 22.63 & 25.97 & 22.87 & 15.38 \\
Median age first trans to alone & 22.75 & 22.54 & 22.29 & 22.14 & 21.81 & 21.55 \\
Median time spent alone & 3.13 & 3.02 & 2.92 & 2.90 & 2.81 & 2.70 \\
\hline
\end{tabular}



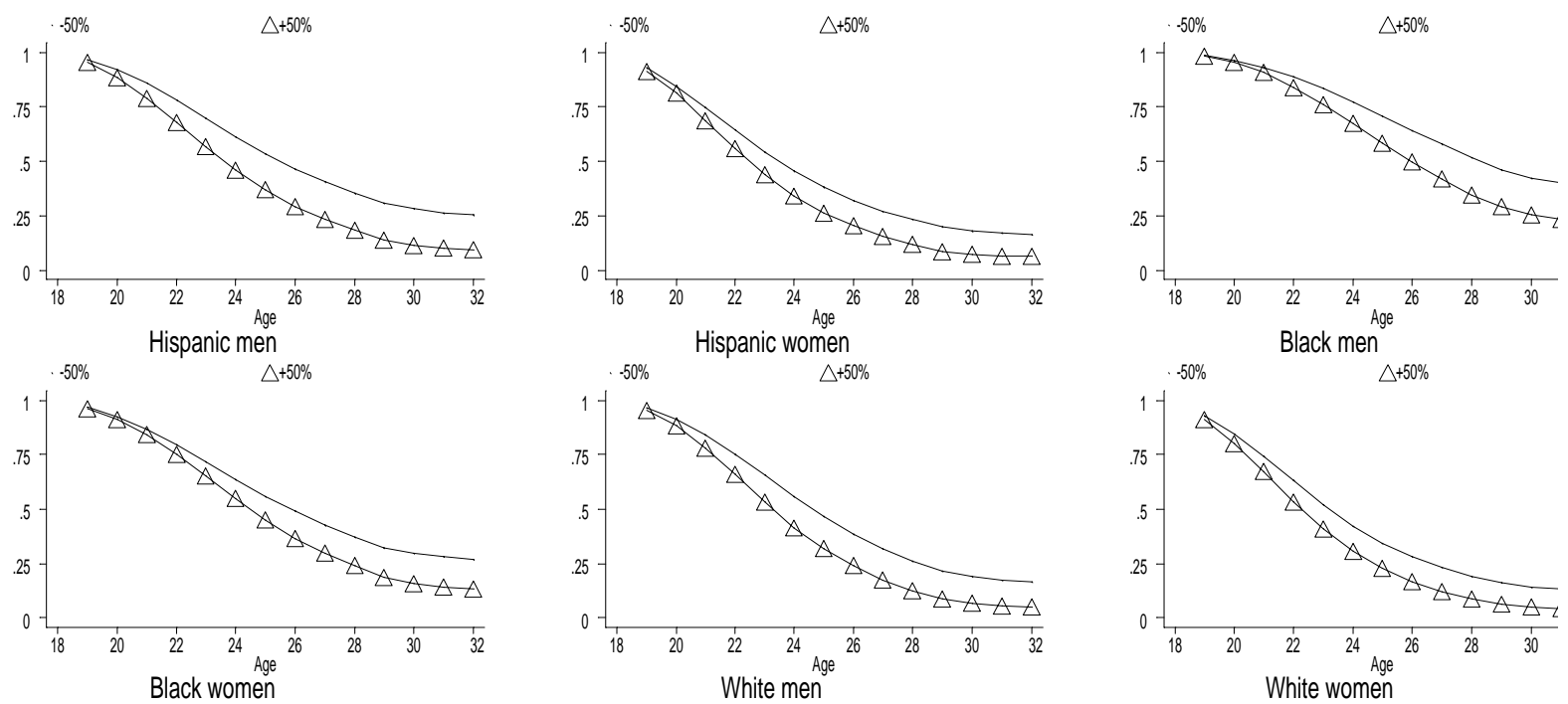

Figure 2: Simulated mean age at marriage for different income groups

\section{Concluding remarks}

This paper examines the transitions from home to marriage of young Americans and the role of income in determining these transitions. We draw attention to the importance of movement out of the parental home into independent living, and back again as well as movements out of home or independent living to marriage. Raw data from the NLSY indicates little association between own income and timing of marriage, and previous empirical research finds mixed results on the impact of either own or parental income on these 
transitions. We put forward an economic model based in search theory to explain these transitions and identify a 'good catch' effect which increases the rate of marriage, and a 'self-reliance' effect which hastens movement to independent living but delays marriage. Using a multi-state, multi-cycle model which allows for correlated unobserved heterogeneity on both the first movement out of the parental home and subsequent transitions, we estimate the effect of own resources, those of the individuals' family, and other measures of an individual's quality and tastes on the timing of these transitions. We find that income has a strong and significant effect. Higher current own resources increases the rate of both the departure from the parental home and the rate at which individuals get married: the net effect is to increase the rate of marriage. In contrast, higher parental resources delay departure from home and delay marriage.

Our results suggest that transitions are affected rather differently by different types of resources. Parental resources and higher investment in human capital make individuals wait, but conditional on these measures of wealth, an increase in current own income speeds up transitions both to living alone and to into marriage. If this is the case, we would expect to see the household formation of young adults to be closely linked to the business cycle: when real incomes rise young individuals move faster, and so form more households: when real incomes fall they move slower and form fewer. This suggests an interesting avenue for further research.

\section{References}

[1] Akerlof, G., J. Yellen, and M. Katz (1985), "An Analysis of Out-ofwedlock Childbearing in the United Sates", Quarterly Journal of Economics, 61(2), 277-318.

[2] Avery, R., F. Goldsheider, and A.J. Speare, (1992), "Feathered Nest/Gilded Cage: Parental Income and Leaving Home in the Transition to Adulthood", Demography, 29, 375-388.

[3] Buck, N. and J. Scott, (1993), "She is Leaving Home: But Why? An Analysis of Young People Leaving the Parental Home", Journal of Marriage and the Family, 55, 863-874. 
[4] Burdett, K. and M. Coles, (1996) "Marriage, Matching and Dynamics", University of Essex Working Paper.

[5] Burdett, K. and T. Vishwaneth, (1988), "Declining Reservation Wages and Learning", Review of Economic Studies, 60, 655-666.

[6] Cole, N. and J. Currie, (1994), "Reported Income in the NLSY: Consistency Checks and Methods for Cleaning the Data", NBER Technical Working Paper.

[7] Goldscheider, F. K. and J. DaVanzo, (1985), "Living Arrangements and the Transition to Adulthood", Demography, 22, 545-563.

[8] Greenstein, T. N., (1995), "Gender Ideology, Marital Disruption, and the Employment of Married Women", Journal of Marriage and the Family, 57, 31-42.

[9] Haurin, D. R., P.H. Hendershott, and D. Kim, (1993), "The Impact of Real Rents and Wages on Household Formation", Review of Economics and Statistics, 75, 284-293.

[10] Heckman, J. J. and B. Singer, (1984), "A Method for Minimising the Impact of Distributional Assumptions in Econometric Models for Duration Data", Econometrica, 52, 271-230.

[11] Lancaster, T., (1990), "The Econometric Analysis of Transition Data", CUP, Cambridge.

[12] Lichter, D. T., D. K. McLaughlin, G. Kephart, and D. J. Landry, (1992), "Race and Retreat from Marriage: A Shortage of Marriageable Men?", American Sociological Review, 57, 781-799.

[13] Lillard, L.A., M. J. Brien, and L. J. Waite, (1995), "Premarital Cohabitation and Subsequent Marital Dissolution: A Matter of Self-selection?", Demography, 32, 437-457.

[14] McLaughlin, D., D. T. Lichter, and G. M. Johnston, (1993), "Some Women Marry Young: Transition to First marriage in Metropolitan and Nonmetropolitan Areas", Journal of Marriage and the Family, 32, 437-457. 
[15] Michael, R. T. and N. B. Tuma, (1985), "Entry into Marriage and Parenthood by Young Men and Women: The Influence of Family Background", Demography, 22, 515-543.

[16] Mincer, J., (1974), "Schooling, Experience and Earnings", Columbia University Press, New York.

[17] Moffitt, R., (1990), "The Effect of the U.S. Welfare System on Marital Status", Journal of Public Economics, 41, 101-124.

[18] Mortensen, D. T., (1986), "Job Search and Labour Market Analysis", North Holland.

[19] Newman, J. L. and C. E. McCulloch, (1984), "A Hazard Rate Approach to the Timing of Births", Econometrica, 52, 939-961.

[20] Rindfuss, R. D., (1991), "The Young Adult Years: Diversity, Structural Change, and Fertility", Demography, 28, 493-512. 